\title{
DEVELOPING RESOURCES FOR TEACHING AND LEARNING CELL AND PARASITE CULTURE WITHIN THE DMU E-PARASITOLOGY PACKAGE
}

\author{
A. Peña-Fernández ${ }^{1}$, C. Hurtado ${ }^{2}$, C. del Águila ${ }^{2}$, M.D. Evans ${ }^{1}$ \\ ${ }^{1}$ School of Allied Health Sciences, De Montfort University (UNITED KINGDOM) \\ ${ }^{2}$ Facultad de Farmacia, Universidad San Pablo CEU (SPAIN)
}

\begin{abstract}
Cultivation of parasites is not a routine identification technique for human parasitic diseases but provides invaluable help in patient care, research and epidemiology, particularly in the diagnosis, management, control and prevention of these diseases. Moreover, culture facilitates students' learning and understanding of the complex morphology, physiology, life cycle and host-parasite relationships of parasites. However, cultivation of parasites can be fastidious and requires specific techniques, resources and skills that may not be available in many biomedical laboratories. Thus, among other factors, cultivation of specific forms of some parasites or species requires in vitro culture of cells to be successful. For example, the emerging human protozoan pathogen Enterocytozoon bieneusi, the most frequently diagnosed microsporidial species in humans, has been successfully cultured only in short term cultures (6 months) and requires animal cells. An innovative teaching group of academics from De Montfort University (DMU), University of San Pablo CEU (USP-CEU, Spain) and University Miguel Hernández (Spain), in conjunction with clinicians and practising Biomedical Scientists from the UK National Health Service are developing on-line resources for teaching and learning the different steps and phases for cultivating mammalian cells (including human cells) and parasites in a biomedical laboratory. These resources or units will be a key part of the "virtual laboratory" section of the novel package DMU e-Parasitology, which will be publicly accessible through the DMU website later in 2018 (http://parasitology.dmu.ac.uk). Cell culture related units are being developed in close collaboration with academics that have built a real cell and parasite culture laboratory. Specific units that describe the basic equipment and resources to cultivate cells and these organisms in a standard biosafety level 2 (BSL-2) medical laboratory (e.g. biological safety cabinet class II, incubators, sterilization, cryogenic storage and inverted microscope) and its workflow are being developed. These units will be highly interactive and engaging and will present short videos of a technician/scientist working in real conditions with this equipment to enhance students' understanding and learning. Short formative assessments will be introduced to facilitate the self-evaluation of users' learning. Finally, photographs and short videos of different human parasites in different media and cultures are being produced and introduced in the "virtual microscope" section of the DMU e-Parasitology. Users will be able to zoom in and out and move around of each sample simulating real parasite cultures. Moreover, students will be able to gain a complete understanding of the different structures and characteristics of major human parasites for clinical diagnostic purposes. We consider that the novel teaching and learning resource $D M U$ e-Parasitology will help students and academics around the world in the teaching and study of human parasitology, making this relevant subject more interesting. Academics will be able to enrich their strategies for teaching and make their sessions more appetising and stimulating. Finally, $D M U$ eParasitology could help educators in course development and could be used for training purposes by future technicians that will work in a cell or parasite culture laboratory.
\end{abstract}

Keywords: DMU e-Parasitology, teaching and learning parasitology, cell and parasite culture, elearning.

\section{INTRODUCTION}

Human cell culture is important for many in vitro studies examining fundamental processes in cell and molecular biology, disease processes and as a first stage in the development of therapies. Many of the practices of human cell culture are applicable to the culture of parasites. This techniques constitute a substantial segment of present-day study of parasites, especially of protozoa. Different parasites require different cultivation conditions such as nutrients, temperature and even incubation conditions. Cultivation is an important method for diagnosis of many clinically important parasites, for example, Entamoeba histolytica, Trichomonas vaginalis, Leishmania spp. and free-living amoebae [1]. Indeed human or animal cells may be required for the culture of obligate intracellular parasites such as 
Plasmodium spp. and emerging protozoan pathogens such as Enterocytozoon bieneusi Cultivation of parasites is invaluable for a number of reasons, which may be broadly outlined as follows [1]:

- Patient Care: cultivation is an important adjunct to diagnosis of many clinically important parasites.

- Research: parasite cultivation may be used to study the biochemistry, physiology of parasites.

- Epidemiology: cultivating parasites may help in differentiating clinical isolates.

- Teaching: parasite cultivation is important for demonstrating the characteristics of pathogenic parasites to student.

Although the practice of parasite cultivation is very diverse, there are certain principles which are broadly applicable to parasite culture. Cell cultures are used for obligate intracellular parasites, for example Plasmodium spp. and coccidian [2,3]. Various types of nutrient such as blood, serum, haem, egg, peptone, minerals and carbohydrates are used in the culture media. [3,4]. The temperature required for optimum growth is usually $37^{\circ} \mathrm{C}$ although lower temperatures may be required in few cases, e.g. $25^{\circ} \mathrm{C}$ for Leishmania promastigotes [3]. Incubation conditions are aerobic with some exceptions, such as the microaerophilic conditions for amoebae and Giardia and $5 \% \mathrm{CO}_{2}$ for Plasmodium spp. [2,5]. Identification tools include the parasite's characteristic morphology, direct fluorescent antibody assay, polymerase chain reaction, enzyme immunoassay, etc. [3,4]. Positive controls should be run in parallel to keep a check on the medium and the method used [1].

For many students the processes and practices of cell culture are mysterious and challenging. As part of the DMU e-Parasitology e-learning initiative a number of mini-modules have been developed in the virtual laboratory area of this package including cell culture and related procedures. Other techniques described include light microscopy, enzyme-linked immunosorbent assay (ELISA), polymerase chain reaction (PCR), electrophoresis and more fundamental procedures such as pipetting. The strategy in developing these technique-based modules is to provide a compact, comprehensive, visually appealing and straightforward delivery of content exploiting extensive use of images and videos. Learning and mastering laboratory techniques is best achieved kinaesthetically and prior to direct laboratory experience visual presentation of processes as images and videos plus accompanying text is seen as a reliable teaching strategy for such practical techniques [6].

\section{METHODOLOGY}

Powerpoint slides containing the information as text boxes, photographs and videos were used as a storyboard to enable DMU software developers to enhance the content and visual appeal and introduce an element of uniformity with existing modules. The team at Universidad San Pablo CEU is developing the parasite culture content for introduction to the virtual laboratory area of $D M U$ eparasitology. A DMU frontrunner (a DMU scheme to employ current students on a part-time basis to support staff in various activities, which also serves as a route for personal development and CV enhancement for the intern in addition to a financial incentive) was employed on a part-time basis to perform photography and develop video footage of the relevant laboratory procedures. The intern was also tasked with editing photographs and videos for use in the Powerpoint presentation. Still photographs of materials and reagents were taken and as necessary close up shots of items. Video footage was taken of a member of academic staff performing procedures in the cell culture suite, again certain procedures were filmed in close up. The use of existing material from the internet would likely have given rise to copyright issues, hence original images and videos were made internally, although there was still a need to contact manufacturers of individual, identifiable items to request permission for use of these items in the module photographs and videos

\section{RESULTS}

Production of module content to demonstrate a multi-step and relatively complex technique such as cell culture can prove challenging and requires the instructor to 'deconstruct' the technique into its component parts. The cell culture module was developed based on existing modules developed earlier in the programme to include learning objectives, background information on cell culture, materials and reagents used in cell culture and the various techniques and processes used to freeze, revive, sub-culture and count cells along with processes for the maintenance of cleanliness and integrity in the cell culture facility. Background information on the operation of large items of equipment, for example the operation of a class II safety cabinet and incubator was also developed. 
The learning objectives for the module are as follows:

- Describe the general principles of human cell culture.

- Show an understanding of the materials and equipment routinely used in human cell culture.

- Describe the processes of freezing, reviving and maintaining human cells in culture.

- Explain the procedures needed to maintain an aseptic environment for human cell culture The module content is summarised in Table 1.

Table 1. Overview of the human cell culture module in DMU e-Parasitology.

\begin{tabular}{l|l}
\hline \hline \multicolumn{1}{c|}{ Topic } & \multicolumn{1}{c}{ Coverage } \\
\hline Introduction & General principles including aseptic technique, types of cell line. \\
\hline Pipetting & $\begin{array}{l}\text { Types of pipette used including sterile graduated pipettes, } \\
\text { autoclaving. }\end{array}$ \\
\hline Cell culture plastics & Types of tubes, flasks and plates \\
\hline Cell culture media \& reagents & $\begin{array}{l}\text { Types and composition of media, additives, additional reagents } \\
\text { for culturing e.g. phosphate-buffered saline }\end{array}$ \\
\hline The cell culture room & $\begin{array}{l}\text { Use of water bath at } 37^{\circ} \mathrm{C}, \text { the incubator, principles of operation } \\
\text { of class Il safety cabinet }\end{array}$ \\
\hline $\begin{array}{l}\text { Preparing the cabinet and in cabinet } \\
\text { manipulations }\end{array}$ & Video of pre-work cleaning procedure, aseptic technique \\
\hline Sub-culturing cells & $\begin{array}{l}\text { Videos of sub-culturing procedure and background information, } \\
\text { e.g. passage number }\end{array}$ \\
\hline Cell counting & Video of cell counting procedure; materials and calculations \\
\hline Cell freezing \& storage & Cell freezing procedure, reagents \& equipment \\
\hline Cell revival & Flow diagram of cell revival procedure \\
\hline Cell culture cleanliness \& integrity & $\begin{array}{l}\text { Materials used for cleaning and disinfecting; sources of infection } \\
\text { and control in cell culture. }\end{array}$ \\
\hline \hline
\end{tabular}

In addition to textual description, audio files with sub-titles are used occasionally to embellish and provide additional content. The frequent use of images (Figs 1-4) to illustrate materials and equipment, as well as aspects related to biology to explain selected situations such as overgrown flasks of cells (Fig. 5). The execution of techniques are also illustrated with appropriate use of video, stills are shown in Figs. 6 and 7. All images shown have been generated by the project team (Peña-Fernández et al., 2017) and copyright ownership is with De Montfort University, Leicester.

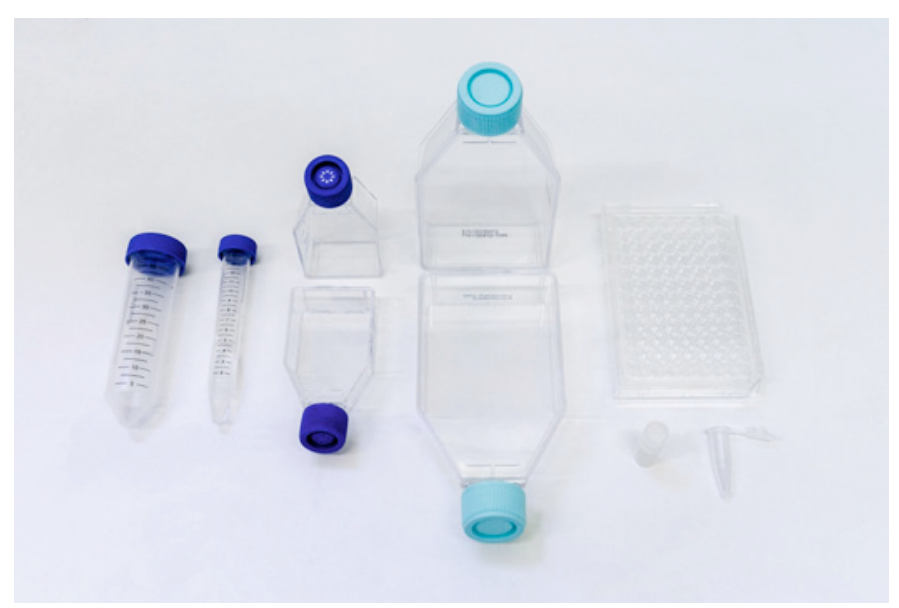

Figure 1: Typical module photograph in this case used to illustrate cell culture plasticware. The image is accompanied by text description of each item. 


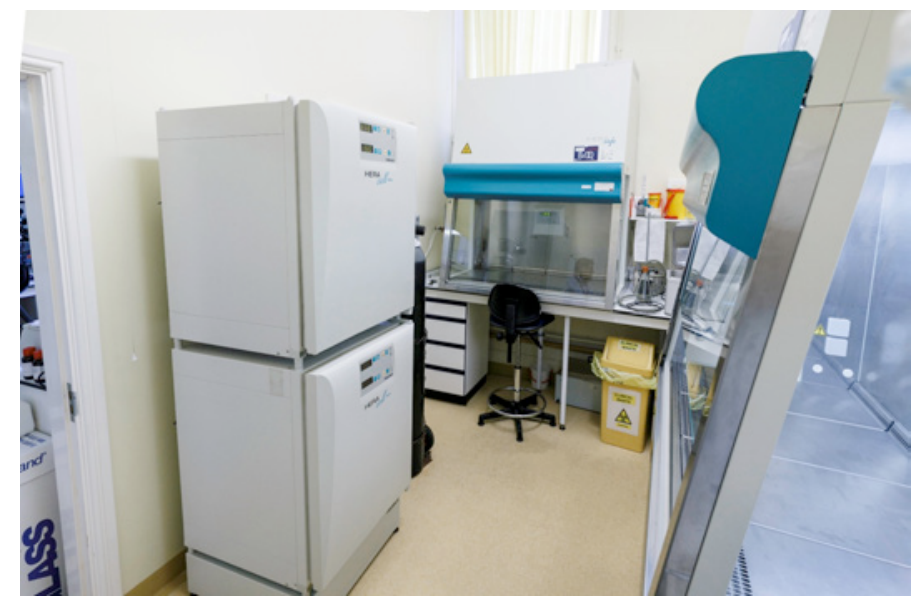

Figure 2: Overview of a cell culture facility.

Each item of major equipment is subsequently described in varying levels of detail.

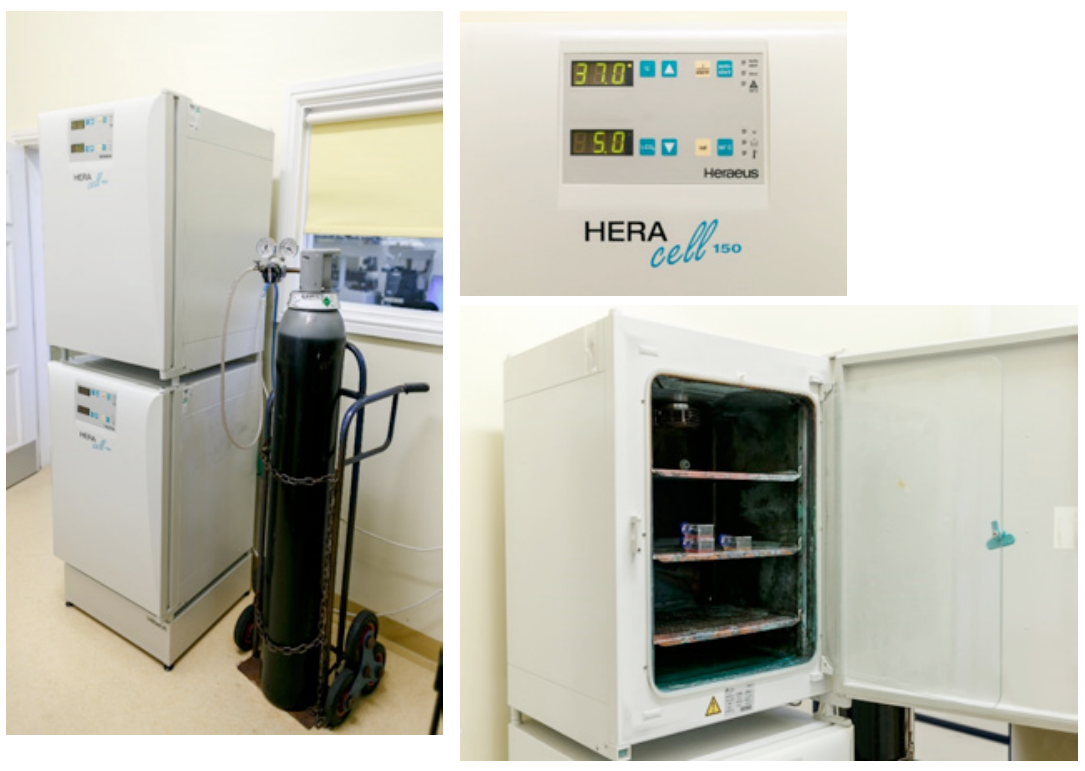

Figure 3: Images of cell culture incubator.
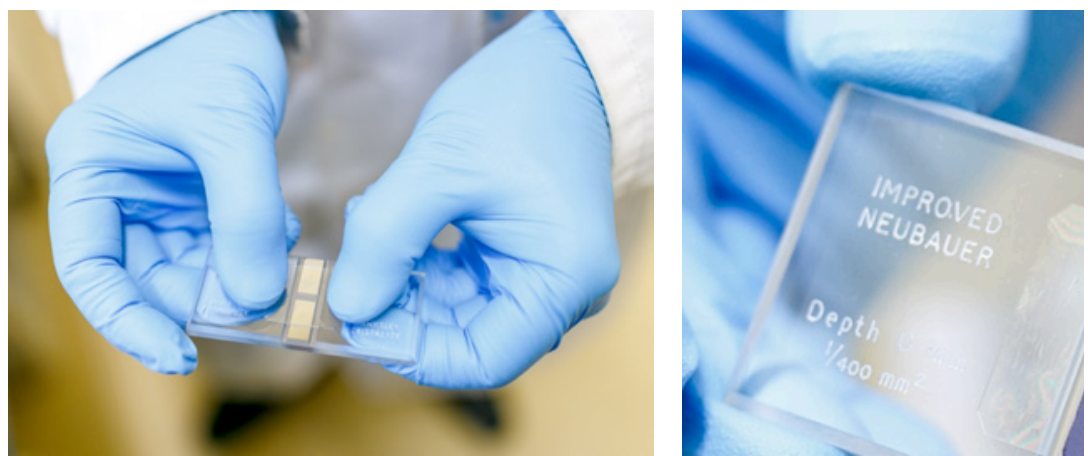

Figure 4: Module image - Close-up images to help understand use of a haemocytometer for cell counting 


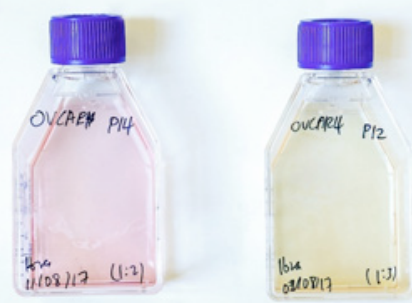

Figure 5: Module image - Illustration of overgrown cells.

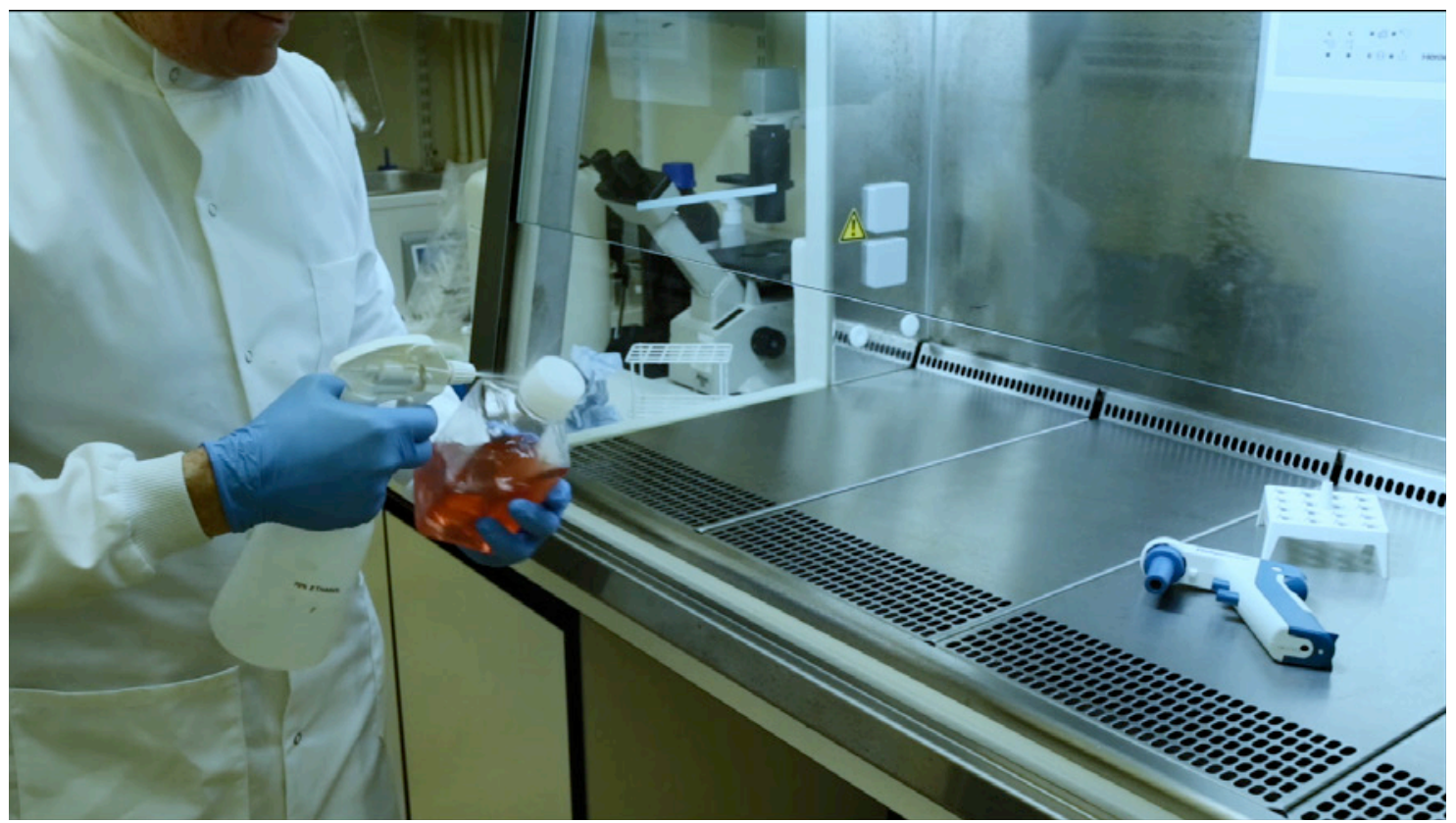

Figure 6: Still image from module video illustrating preparation of class II cabinet for use.
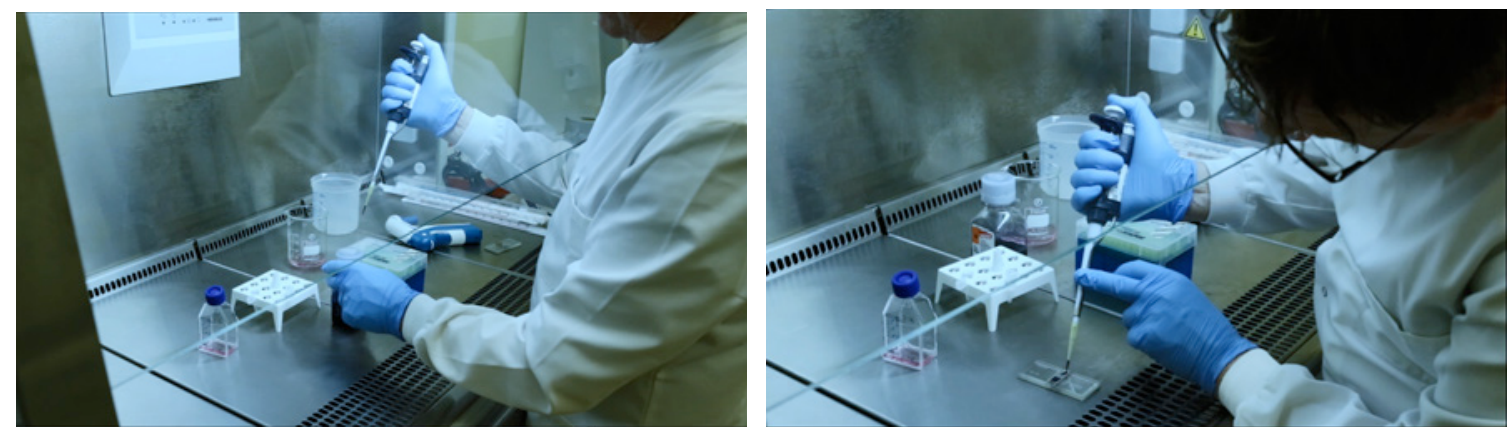

Figure 7: Still images from module video illustrating sampling and preparation of cells for counting using haemocytometer, with close up of filling counting chamber later in video.

A series of three formative assessments is also being developed for inclusion in the module at the end of each major section to test learners' knowledge of the preceding content. This will include multiple choice and image-text matching type questions of varying difficulty. More challenging questions requiring the learner to put the module material into a less familiar context, rather than simple knowledge recall is proposed, to test/enhance critical thinking. 


\section{CONCLUSIONS}

The anticipate that the novel teaching and learning resource DMU e-Parasitology will be a global resource to help students and academics in the teaching and study of human parasitology, making this relevant subject more interesting. Academics will be able to enrich their strategies for teaching and make their sessions more appetising and stimulating. Finally, DMU e-Parasitology could help educators in course development and could be used for training purposes by future technicians that will work in a cell or parasite culture laboratory.

\section{ACKNOWLEDGEMENTS}

The authors would like to express their sincere appreciation to the following: Steve Mackenzie, Jonathan Coope and Maxine Armstrong (DMU) for their work in software development of DMU eParasitology; DMU Frontrunner intern Mr. Marek Kowalik for photography and video production; the Teaching Innovation Project Fund at De Montfort University (scheme 2015-16) to fund this project to Dr. Peña-Fernández.

\section{REFERENCES}

[1] N.H. Ahmed, "Cultivation of parasites", Trop Parasitol., vol. 4, no. 2, pp. 80-89., 2014.

[2] F.L. Schuster, "Cultivation of Plasmodium spp.", Clin Microbiol Rev., vol. 15, pp. 355-364, 2002.

[3] M.J. Arrowood, "In vitro cultivation of Cryptosporidium species", Clin Microbiol Rev., vol. 15, pp. 390-400, 2002.

[4] G.S. Visvesvara and L.S. Garcia, "Culture of protozoan parasites", Clin Microbiol Rev., vol.15, pp. 327-328, 2002.

[5] C.G. Clark and L.S. Diamond, "Methods for cultivation of luminal parasitic protists of clinical importance", Clin Microbiol Rev., vol. 15, pp.329-341, 2002.

[6] M. Truebano and C. Munn, "An Evaluation of the Use of Video Tutorials as Supporting Tools for Teaching Laboratory Skills in Biology", Pract. Eviden. Schol. Teach. Learn. Higher Educ., vol. 10, no. 2, pp. 121-135, 2015 